\title{
Chapter 6 \\ Virtuality and Fostering Critical Design \\ Thinking: An Exploration of the Possibilities \\ Through Critical Theory, Design Practices \\ and Networked Learning
}

\author{
Caroline Newton and Burak Pak
}

Arguably the twenty-first century is characterised by a myriad of challenges and a rapid pace of change and troublesome conditions, such as the environment, the global economic crisis and numerous conflicts of all sorts. It is within this context that our plea for increased critical thinking and critical design is situated. Projects such as the Bird's Nest in Beijing or the Olympic Village in London have all been extensively covered by both mainstream and specialised architectural press. In all these projects, the spotlight of attention has been on the design and the designer. The 'Starchitects', a term used to refer to world-famous architects who have achieved a sort of celebrity or an idol status, are at the centre of the attention. The choice of cities and developers to create iconic buildings, designed by these celebrity architects, can be understood as ways to create more profit or to become global cities. The context of the design and the neighbourhoods around these and the daily life experience of the people these projects are interfering with seem of lesser importance.

Unfortunately, this imbalance between the attention for the design product and its designer on the one hand and the intended or the future audience on the other is also present in the design studio pedagogy as it is being employed in most schools of architecture. This imbalance truly conflicts with the initial conceptualisation and theorised possibilities of studio-based learning approaches (Schön, 1987). In parallel to these developments, the technological evolution of the last decades not only

\section{Newton $(\bowtie)$}

The Bartlett Development Planning Unit, UCL, London, UK

e-mail: caroline.newton@mac.com

B. Pak

Faculty of Architecture, KU Leuven, Leuven, Belgium

e-mail: burak.pak@gmail.com 
enabled projects with complex structures such as the Bird's nest or location-aware installations such as the Toyo Ito's Tower Winds in Tokyo, but have also led to the creation of virtual realms in which online networked learning communities (NLC) (De Laat, 2006, p. 86) open new opportunities to reinvigorate the social tasks of the architect during the educational trajectory.

In this contribution we connect the social turn in architecture practice and education with the innovative possibilities that emerge from the integration of networked learning in design education. We work through three interactive arguments:

- Critical thinking and a critical attitude are essential for the creation of innovative ideas, concepts or solutions that go beyond the current conditions and problems grounded in the existing conventions of society.

- Critical thinking should be an essential part of the architectural design practice, education and most importantly the design studio as its central element.

- Networked learning (Goodyear, Banks, Hodgson, \& McConnell, 2004) has a strong potential to foster critical thinking in the architectural design studio because it can facilitate the redefinition of the existing traditions in previously unimagined ways.

The usefulness and importance of critical thinking has been the topic of debate for educators, psychologists, philosophers and social theorists (Dewey, 1933; Mezirow, 1981; Smith, 2011, Steier, 1991; Wilson, 2002). Critical thinking is usually understood as a reflective investigation in one's own thinking and related behaviour. Through the examination of one's own thoughts, it is possible to learn who we are and how the beliefs we hold and the worldview we have influence our thinking and action. Critical thinking allows us to become aware of our positionality (Foucault, 1982; Giddens, 1976, for example see Schuermans \& Newton, 2012).

Demonstrating the importance of the critical design thinking approach, we aim at investigating the current practice of architectural education. We position and question its own reasoning, and illustrate an alternative way to approach architectural practices, education, as well as the relation of these practices to information and communication technologies (ICT).

In this context, we start with an analysis of the current situation of architecture as a profession in close relation with architectural education and the design studio as its central element. In what follows we first elaborate on the notion of critical thinking and situate it with the notions of critical design and critical architecture within the broader frame of critical theory. Then we stress the importance of integrating critical thinking in architectural education and practice. Examining the existing situation, we critically approach the problems associated with the architectural design practices.

Next, we address the social turn in architecture; as this shift enforces the need for a critical approach to architecture and a networked learning pedagogy that allows students to incorporate the necessary skills of collaboration and critical thinking. We deconstruct the current configuration and operational modes of the design studio in 
architectural education, and relate these to a discussion on the role of students and practising architects as users. Furthermore, we introduce a typology of virtual realms to explore their significance for integrating critical (design) thinking in architectural education. In the final section, we derive conclusions and draw future prospects for the integration of a social attitude as a product of our critical standpoint.

\section{Critical Thinking and Critical Design in Context}

Critical thinking as employed in this chapter is rooted in Neo-Marxist ideology interpreted within the tradition of critical theory through the contributions of the Frankfurt school and its translation in the disciplines of planning and design by Peter Marcuse (2009). As Brenner (2009) clearly explains, critical theory is reflexive, it explicitly engages with normative questions and thus rejects an instrumental use of scientific knowledge. Moreover, it 'emphasizes the disjuncture between the actual and the possible' (Brenner, 2009, p. 203) and seeks to 'liberate human beings from the circumstances that enslave them' (Horkheimer, 1982, p. 244).

From the definitions above, it is clear that critique and critical theory are about politics. In this sense, thinking critically and by extension designing critically is about being political and engaged. Both in critical thinking and critical design we have to be conscious about the context in which we operate, as it also influences our thinking and designing. In this sense, critical thinking is essential for design because it reveals how subjectivity and alternative forms of knowledge manifest themselves in a specific social and historical context (Brenner, 2009). A critical design approach is grounded in the knowledge that design is never neutral: it is shaped and formed by the society and the system it was developed in. Therefore, designing architecture, and especially public spaces, is naturally 'a form of politics' (Eisenman, 2012).

In the current capitalist society, it can be argued that design enforces values of capitalism (Dunne, 1999; Dunne \& Raby, 2001; Melles \& Feast, 2013). The same can be claimed for architectural artefacts. The Modernist designs of Le Corbusier such as Plan Obus for Algiers and many other works of his followers are true examples that support these statements (Jencks, 1987, p. 12). Although the Modernist movement argued that they pushed forward a new and better society, they develop the ideas that came from the minds of a few 'enlightened' thinkers-architects. What they showed in the end is a tomorrow for a small elite, designed from within that worldview. The Modernist city of the future is therefore not a social paradise based on equality. Instead, it enforces the existing social power relations and the capitalist tendencies (Bloch, 1995).

Today we see that architecture and urban design increasingly strengthen consumerism and segregation. Madanipour (2010, p. 2) explains that 'the development and use of public spaces mirror the way a society is organized, shaped by unequal distribution of power and resources'. The proliferation of shopping malls and gated 
communities illustrates his point. In contrast, in a handful of locations, counter urban design approaches are slowly emerging and grabbing the attention of alternative media. Preliminary examples of these small-scale interventions are Guerrilla gardening (in London) and Pavement-to-parks (various locations in the USA) which fall into the 'tactical urbanism' movement. It is possible to draw parallels between critical design and tactical urbanism, but different than the latter, critical design specifically aims to imagine alternative possibilities for the current state of affairs through a continuous interaction of reflection and action (Melles \& Feast, 2013). Therefore, critical design involves the constant questioning of politics and dominant (capitalist) values.

Dunne and Raby explain that in order to get a better understanding of a preferable world it is necessary 'to move beyond designing for the way things are now and begin to design for how things could be, imagining alternative possibilities and different ways of being, and giving tangible form to new values and priorities' (2011, p. 131). They suggest designers to work together in a dialogue with people in the fields of ethics, philosophy, political science, life sciences and biology. This kind of collaboration requires the development of an attitude of dialogue which needs to be nurtured during the education of the architectural designers. Consequently, architects can avoid playing the safe role of 'administrators' solely answering the demands of the clients controlling the capital.

Contemporary architectural design practices require effective participation and mutual learning. Especially in large-scale projects, it is becoming quintessential to enable innovative forms of learning through which a high number of inhabitants can critically construct knowledge and share their problems, needs, future goals as well as novel ideas.

The above implies that architectural education, at present, needs to be put under scrutiny, and the design studio as its core should be deconstructed. We need an approach in which norms and values are integrated and which embeds a more social attitude into the educational trajectory, assisted by technological innovations and networked learning pedagogies. In this sense, the integration of various social and geographic learning platforms and virtual environments can potentially enable new constructivist learning modes; particularly in socio-spatially situated and media-rich learning contexts. In a nutshell, these environments are "computer-generated, persistent spaces in which users co-exist as avatars exploring, building, interacting and communicating' (Koutsabasis, Vosinakis, Malisova, \& Paparounas, 2012, p. 1).

In the context of architectural design learning, we think of these in an inclusive manner. Possible examples include Second Life and OpenSim, as well as the multi-user virtual globes such as Google Earth, augmented reality environments such as Wikitude and web-based hybrid geographic platforms (Pak \& Newton, 2015). When combined with novel learning strategies through a networked learning approach, these technologies can promote and augment rigorous discussion and informed consensus on actions and design problems (Schnabel \& Ham, 2011).

This approach described refers to an 'educational context in which ICT are used to promote collaborative and cooperative connections - between one learner and other learners; between learners and teachers; between a learning community and its learning resources - so that participants can extend and develop their understanding 
and capabilities in ways that are important to them, and over which they have significant control' (Banks, Goodyear, Hodgson, \& McConnell, 2003, p. 1). Through the use of networked learning approach, it is possible to enhance our powers of observation, create richer and authentic learning experiences in which the learners collaborate in creating new knowledge and extend their own understandings (Lloyd, 2010). On the other hand there is a need for more attention to criticality in the networked learning practices (Mann, 2004, p. 216).

\section{The Social Turn and Architectural Design}

The proliferation of information and communication technologies in the last decades has enabled architects and designers to design in a radically new way and provided the technical solutions and material innovations to realise designs that were unthinkable before (Jencks, 2011). The products of these designs (e.g. buildings) are getting more intelligent, meaning they are able to respond and adapt themselves to their immediate physical surroundings (e.g. temperature, lights).

For instance, the Weather Tower Project in Brussels can forecast the daily weather and 4,200 windows on the building can individually be lighted by RGB-led bars depending on the temperature and wind changes (LAb[au], n.d.). Such architectural designs are praised because they are supposedly answering the complexities of our current societies. We argue that this is a narrow approach. The technological advancements do not necessarily enable the designers to take the lived realities of our contemporary postmodern and globalised societies into account.

First of all, cities are more than spaces of pure physical composition. Undoubtedly, the built environment reflects the strong intertwinement of space and people. As Lefebvre (1991, p. 26) explains, '(social) space is a (social) product' and 'the space thus produced also serves as a tool of thought and of action [...] in addition to being a means of production it is also a means of control, and hence of domination, of power'. The role of architects and (urban) designers in interfering in this built-up space can thus hardly be underestimated. It is important to recognise that designers have a societal obligation (Newton, 2013). As Bernard Tschumi explains: 'Architects act as mediators between authoritarian power, or capitalist power, and some sort of humanistic aspiration. The economic and political powers that make our cities and our architecture are enormous' (Tschumi quoted in Fraser, 2005, p. 318).

Second, we observe a 'social turn' in architecture. More and more in increasingly, architects and designers start to get interested in housing for the underprivileged in our societies, often in exotic places. This call of the informal has been attracting an increasing number of professionals, academics, and designers. Unfortunately in some cases, the attraction is based on the interest in the aesthetics and innovative designs, as is illustrated in the MoMA exhibition on Small Scale, Big Change, which showcased New Architectures of Social Engagement (Lepik, 2010).

In other cases, an idealisation of the exotic leads to an aesthetic fetishisation of projects such as the Elemental's Quinta Monroy Housing Project, in which the 
residents fill in the provided structure based on their possibilities (Newton, 2013). Newton (2013, p. 131) argues that "when urban designers and architects get interested in informal urbanism it should be for more than the mere "aesthetics". The lived realities of the people who are influenced by these projects have to be more than a playground for the architects. It is insufficient to claim complexity and intelligent user-centred design just because the building looks complex or because it offers several solutions within one building.

\section{Problems with the Architectural Design Practices and Education}

Building on a long tradition of critical theory, and more specifically on Foucault (1980) and Deleuze and Guattari (2004), we acknowledge that every act we undertake as architects not only directly influences people's living environments, but also shapes or confirms societal/political discourses. Therefore architects and designers can no longer take the position as objective administrators, despite the difficulties this brings (see also Davidson, 1995; Fraser, 2005). Relating Furedi's (2006) claim that 'being an intellectual requires social engagement' with Gramsci's (1992) conceptualisation of an intellectual we want to stress that the same moral and social engagement should be taken by architects. This need has to be addressed during the educational process of the student-architect.

It was Schön (1983) who called for an "epistemology of practice implicit in the artistic, intuitive processes which some practitioners do bring to situations of uncertainty, instability, uniqueness, and value conflict', he referred to this as 'reflective practice'. In the following years this strand of reasoning was further developed by people such as Cross, Christiaans, and Dorst (1996), Akin (1997) and others leading to the belief that just as the sciences have their own underlying forms of knowledge, so has design. As such design has its own ways of knowledge production, thinking and acting (Cross, 2001).

A 'designerly way of knowing' (Cross et al., 1996) is able to reinterpret existing problems, or more broadly questions, and to develop solutions that have been unthought-of before. A designerly way of knowledge production does offer possibilities to go beyond the hegemonic university discourse based on strict science (Newton \& Boie, 2011). Lacan (2006) has argued that dominant thoughts and principles in a society are unlikely to be contested by the apparent 'neutral' knowledge produced at the university. In contrast to this architects and artists have historically been important actors in the development of (creative) innovations (De Graeve, 2010). We argue that today this creative and innovative practice is more than ever needed. The hegemonic position of the so-called scientific knowledge, supporting dominant beliefs needs to be contested and our humanistic heritage needs to be rediscovered.

In order to achieve this aim, architects need to develop ideas, concepts and solutions that are grounded in the current conditions described by Bloch (1995 (1938-1947), 
p. 13): 'Every solid daydream intends this double ground as homeland; it is the still unfound, the experienced Not-Yet-Experience in every experience that has previously become'. Thus the education of future architects needs to foster this utopian attitude, and proposed design alternatives need to go beyond the current condition. A 'Utopian attitude' (not to be understood in the modernist's sense, but Utopian as Bloch (1995, p. 13) understood it) will be a crucial part of the formation of urban planners and architects. We argue that, as architects, we need to critically think about our current society and envisage a future-more inclusive and equal one. Inclusiveness requires valuing other human beings and the importance of equality, and equality is understood when the importance of collective responsibility and action is obvious (Machel, 2010; Newton \& Boie, 2011).

\section{Reflections of Architectural Practices on the Architectural Design Education}

When we reflect the issues above on architectural design education and build further on Cross's (2006, pp. 4-5) reading of Peters (1965), we can deduce three principle criteria:

1. The transferred knowledge should be worthwhile.

2. The way people are educated is as important as the knowledge being worthwhile (not imposing, deliberative learning).

3. Mere knowledge is not enough: understanding and positioning one's knowledge in relation to other things is imperative.

Consequently, future architectural and urban design professionals need to be able to develop a socio-spatial cognition; a knowledge and understanding of the sociospatial intertwinement. To achieve a true understanding and be able to think critically about the material and ideas that are being presented throughout the education trajectory, mere listening to the teacher will not suffice. Argyris and Schön (1978, p. 3) called this 'double loop learning'. This type of reflective learning takes place when practitioners critically question the underlying norms, policies and objectives of an organisation with the purpose of further improvement.

Parallel to Schön, Mezirow (1997) speaks about the need for transformative learning. Transformative learning aims to help the students to re-examine their understanding of the world and revise their belief systems and behaviour (Clark \& Wilson, 1991; Mezirow, 1997). He goes on to argue that merely providing new information is not enough. The information needs to be incorporated by the students in their own frames of reference, this requires an active process of critical (self-) reflection. The kind of education that fosters this needs to be 'learner-centered, participatory, and interactive, and it involves group deliberation and group problem solving' (Mezirow, 1981, p. 10).

Another important aspect to consider is that education is more than mere training and 'knowing that' (Cross, 2006, p. 5). It is about positioning oneself as an engaged 
building and urban design professional. There is a need for more than merely a curriculum that is solely based on knowledge transfer. We need to stimulate students to think of their own position within the professional field they will enter, and within the world at large.

Such practices require developing ideas, concepts and solutions that reach beyond the current conditions and problems. Thus, we stress that the Utopian attitude, as understood by Bloch (1995, p. 13)) should be a crucial part of the formation of architects (Newton \& Boie, 2011). Integration of novel virtual environments and worlds into the architectural and urban design education provides potentials for redefinition and improvement of power relations as well as promoting interdisciplinary networked learning and participation of students, tutors and other stakeholders.

\section{Problems with the Architectural Design Studio Practices: Do We Need a Reanimator?}

During the course of the twentieth century the design studio has become the heart of architectural and urban design education. This pedagogical model has its roots in the studio-based training at the Ecole des Beaux-Arts in Paris during the nineteenth century, whereby the several aspects of the design discipline are brought together (Kuhn, 2001, p. 349). Structural design, technical aspects and the social implications of a design were all taken into account during the design process. From its conception in the nineteenth century, the design studio offered the possibility to work in a holistic manner on questions and challenges that were being presented to the students.

Thus, studio-based learning holds the promise of realising an educational model in which not merely knowledge is being transferred but one that allows the learners to educate and emancipate themselves. These ideas are underpinned by the humanistic and critical theoretical insights provided by Rancière (1991) and Freire (1970). Both thinkers stress that education is much more than a mere transfer of knowledge from the teacher to the student-instead, it is about enabling the students to educate themselves. In the words of Freire, 'what the educator does in teaching is to make it possible for the students to become themselves' (Horton \& Freire, 1990, p. 181), and Rancière (1991, p. 15), 'one can teach what one doesn't know if the student is emancipated, that is to say, if he is obliged to use his own intelligence'. Boyer and Mitgang describe studio-based learning as:

reflective ... design project centred ... master craft-person supervised ... group size varied (ranging from groups of 20 all the way down to pairs which move freely and change sizes frequently at the learners' will to learn) ... discussion intense ... individual project driven ... highly integrated across multiple knowledge elements of the profession being practiced ... Studio-based ... and fostering of the learning habits needed for the discovery, integration, application, and sharing of knowledge over a lifetime (1996, pp. xv-xvi).

This can be an answer to Schön's definition of the (architectural education) studio as a 'reflective practicum in designing' (Schön, 1987, p. 4), whereby students 
learn not merely by accumulating knowledge but through an ongoing process of 'trial-and-error' (Wang, 2010, p. 175). Thus, it is assumed that the students are being educated in a 'conversation-like' process between the students and the educator who is managing the studio. Valkenburg (2001) and Wang (2010) stress that collaboration, rapid communication and the broad societal relevance are the characteristics of the design studio approach. Schön's (1983) 'reflection-on-action' can be realised in an environment that stimulates dialogue and debate, as in networked learning settings both learners and tutors are on a same level and are able to discuss issues and dilemmas that arise during the studio.

From the above, we argue that a studio-based learning approach holds numerous opportunities to educate future architects in a critical fashion. At the start of design studio exercise, that can run over different weeks, the students get a (design) task or question. In order to develop (design) strategies, students not only research the matter at hand, they also simultaneously start designing and experimenting. In order to do so, students collect information from a large number of disciplines or areas of interest and process these in a nonstructural way.

Possible alternatives or answers to the challenges presented are discussed with both peers and instructors and in an iterative way the student works towards the presentation of the more 'satisficing' answer (Simon, 1969, p. 29). Learning happens in a networked manner, through conversations, collaboration and dialogue. While in the past, these interactions happened in 'real-life', during the studio hours, today we have the opportunities to extend this way of learning in the virtual realms. Students are encouraged to critically engage with their subjects of study and to leave the beaten tracks in search of alternative possibilities.

\section{Criticism of the Architectural Design Studio}

While above we sketch the positive possibilities of a studio-based approach, we must also acknowledge that over the years a problematic 'culture' has developed in both architectural education and practice. When reflecting back on his educational trajectory Mark Howland (1985) explains that:

\footnotetext{
The long hours of work in a common studio space forged us into a close knit group of men and women who were marked by our dedication, endurance and talent. We shared the excitement of learning to see the world in a new way, of learning to distinguish between well and poorly designed glasses while our friends were drinking coffee unaware from Styrofoam cups. We were the imaginative professionals with certified taste.... What the architectural tradition and our mentors suggested and what we students were teaching each other was that boring and conventional people produced boring and conventional designs. We encouraged eccentric dress, hyperbolic speech and unconventional behaviour.
}

It is not difficult to see that one of the implications of this sort of pedagogy is the fostering of an elitist attitude. The Architect, as an enlightened being, should be able to educate the ordinary citizens in the society. Le Corbusier, the most prominent modernist architect of the twentieth century, was influential in this thinking embodying 
a Neo-Platonist position. He was convinced that the universal ideas and pure forms (of harmony) exist outside of our daily reality and that only the educated and enlightened beings (such as architects) were able to know these ideal forms and ideas. Bringing the 'normal people' in contact with the pure and perfect geometries would enlighten them. Authoritarian tendencies develop easily, and certain architects were convinced that this enlightenment, assumingly for the 'people's good', should happen even 'against the people' if necessary (Jencks, 1987, p. 12).

So, although we acknowledge that studio-based learning holds the promise of being able to answer the aforementioned needs regarding the education of the architect in our contemporary and complex society, we also see that in practice this design studio approach contains shortcomings that have effect far beyond mere pedagogy (Koch, Schwennsen, Dutton, \& Smith, 2002; Webster, 2006). There are a number of myths that are present within most schools and design studios.

A first point was revealed by a study of the American Institute of Architecture Students looking at the 'studio culture' in 125 schools in the USA. The research showed that the focus of the studio is still primarily on the final product rather than on the process. Disregarding the process of design also implies that no real attention is paid to the reality in which a design will be situated. Issues of participation or taking into consideration the concerns of future users are disregarded (Koch et al., 2002).

Webster (2006) brings a second important observation to the fore, that studiobased learning in architectural education is still poisoned by an overemphasis on the teacher. Consequently, it hampers a real constructivist education in which both the student and the teacher are on equal foot during the design project/process (based on Rancière's concept of the 'Ignorant Schoolmaster') (see also Newton \& Boie, 2011).

Third, the current emphasis on the design product, together with the emphasis on moments of critique, where students are being evaluated, makes that students work towards a final presentation in front of a jury of 'experts' or 'masters'. These one-off occasions are not only harmful for a healthy student life (e.g. nightlong working, high levels of stress ...) (Koch et al., 2002). They also create a 'skewed' power hierarchy in which students have to justify their work and thoughts to the teacher (and the experts), often in a spatial setting that is only reinforcing this hierarchical relation and often accompanied with a discourse in which the experts show their expertise while at the same time question that of the student (Webster, 2006). We can hardly argue that this way of learning is still 'a reflective conversation with the materials of the situation' (Schön, 1987, p. 4). This approach, whereby the educator presents himself as an authority or expert, rather than a facilitator or provocateur, doesn't stimulate transformative learning (Mezirow, 1997, p. 11).

All this leads to a behaviour that is unhealthy and neither in line with how Schön's envisaged architectural education nor with the set-up of a studio-based learning approach or the ethos of networked learning. On the contrary, this form of education contributes to the development of a type of architects who consider themselves as being experts, being masters in architecture. The Architect has the knowledge and the understanding of making design decisions that are both based on rational reasoning and artistic/aesthetic understanding. The interrelation of these two sides — the architect as expert and the architect as artist—helps to strengthen the 
architect's status as the 'artist-genius', on which 'the architectural culture to the outside world' (Till, 2009, p. 60) strongly builds.

Till (2009, p. 178) is concerned about the role architects should take on, and, building on a large body of literature, develops very strong arguments that 'architecture depends'. The over-focus of architects on the final product and its aesthetics has skewed the overall understanding of the social role of architecture. And although we acknowledge that the role of architects and the role of architecture cannot be conflated we agree with Till, who argues that 'the key ethical responsibility of the architect lies not in the refinement of the object as static visual product, but as contributor to the creation of empowering spatial, and hence social, relationships in the name of other' (ibid). In this context, architects do not require only theoretical or the practical knowledge, but also need to understand their responsibilities within the context of its deployment (see Newton \& Boie, 2011; Shotter, 1993; Till, 2009, p. 166).

\section{Potentials of Virtual Environments for Fostering Critical Design Thinking}

The evolution sketched in the former sections illustrates that the emphasis of the educational practices has shifted from the designed object (from an artefact, to a building, to an urban setting) to the architect-designer. This is problematic in several regards. We still believe that the architect has a role to play in the society, rather than being means to an end. It would be too easy to hide behind the excuses of answering the call of the client, or working within a utilitarian framework which only looks at economic viability and cost minimisation (and thus profit maximisation).

In order to understand how architecture and education could be reanimated, we first look into the current role of the architect within a climate of ongoing neoliberalisation. Table 6.1 compares several domains of contemporary architecture and highlights tensions between educational trajectory which enforce the stereotype of the architect as artist and autonomous thinker, and the daily reality of the architects as 'innocent professionals' who answer the needs of their clients.

In contrast to software engineers or managers, whose work is generally evaluated by anonymous users, clients and customers, the architect is faced with the verdict of expert panels of peers.

The first three columns in Table 6.1 illustrate the limited perspectives of the main target audience (architects), producers, and marketers of the virtual environments. In this sense it is clear that an alternative approach is required. Extending and overriding the above interpretations (Table 6.1, column 4), we reframe and suggest utilising virtual environments as catalysers for the redefinition of the architectural practice and education. In this way, networked learning can foster critical thinking and strengthen the role of the practitioners and students as socially engaged intellectuals as described in the former sections. In what follows we will present some alternative approaches that encourage students to think of their own position within the professional field. We will show how virtual environments can foster critical thinking and innovative thinking. First, we will present the typologies of virtual environments and how we see these at work in architectural education. 
Table 6.1 Professional domains and the architecture professional

\begin{tabular}{|c|c|c|c|c|}
\hline & $\begin{array}{l}\text { Professional } \\
\text { architecture view }\end{array}$ & $\begin{array}{l}\text { Technology- } \\
\text { oriented view }\end{array}$ & $\begin{array}{l}\text { Marketing-/ } \\
\text { business-oriented }\end{array}$ & $\begin{array}{l}\text { Critical } \\
\text { architectural } \\
\text { education }\end{array}$ \\
\hline Participants & Client-architect & User-designer & $\begin{array}{l}\text { Customer- } \\
\text { entrepreneur }\end{array}$ & Critical learners \\
\hline Outcomes & $\begin{array}{l}\text { Built environment } \\
\text { (building, square, } \\
\text { street ...) }\end{array}$ & Software & Value proposition & $\begin{array}{l}\text { Creation of } \\
\text { empowering } \\
\text { spatial and social } \\
\text { relationships }\end{array}$ \\
\hline $\begin{array}{l}\text { Power } \\
\text { distribution }\end{array}$ & $\begin{array}{l}\text { Maintain and } \\
\text { enhance power } \\
\text { distribution }\end{array}$ & $\begin{array}{l}\text { Observation, } \\
\text { improvement } \\
\text { and better } \\
\text { facilitation }\end{array}$ & $\begin{array}{l}\text { Observation and } \\
\text { profit maximising } \\
\text { action }\end{array}$ & $\begin{array}{l}\text { Reconfiguring the } \\
\text { power distribution }\end{array}$ \\
\hline $\begin{array}{l}\text { Virtual } \\
\text { Environment } \\
\text { for ... }\end{array}$ & $\begin{array}{l}\text { Visualisation and } \\
\text { promotion of the } \\
\text { project }\end{array}$ & $\begin{array}{l}\text { Improving } \\
\text { performance } \\
\text { and efficiency }\end{array}$ & Competition & $\begin{array}{l}\text { Critical learning } \\
\text { and critical design } \\
\text { networked learning }\end{array}$ \\
\hline \multirow[t]{6}{*}{ Education } & Architect as artist & \multirow{6}{*}{$\begin{array}{l}\text { Knowledge } \\
\text { and rationality }\end{array}$} & \multirow{6}{*}{$\begin{array}{l}\text { Financial } \\
\text { knowledge/ } \\
\text { markets/ } \\
\text { organisation } \\
\text { and leadership }\end{array}$} & Transformative \\
\hline & Autonomous designer & & & learning \\
\hline & \multirow[t]{4}{*}{$\begin{array}{l}\text { Vitruvius's } 3 \text { virtues: } \\
\text { solidity, usefulness } \\
\text { and beauty (firmitas, } \\
\text { utilitas, venustas) }\end{array}$} & & & $\begin{array}{l}\text { Redefinition, } \\
\text { participation and } \\
\text { mutual learning }\end{array}$ \\
\hline & & & & $\begin{array}{l}\text { Interdisciplinary } \\
\text { dialogue }\end{array}$ \\
\hline & & & & $\begin{array}{l}\text { Enabling context- } \\
\text { consciousness }\end{array}$ \\
\hline & & & & $\begin{array}{l}\text { Creating richer and } \\
\text { authentic learning } \\
\text { experiences }\end{array}$ \\
\hline Evaluation & $\begin{array}{l}\text { Crit panels of } \\
\text { experts (architect } \\
\text { practitioners) }\end{array}$ & User panels & 'Market system' & $\begin{array}{l}\text { Integrated/expanded } \\
\text { jury: NGOs, } \\
\text { representatives of } \\
\text { the users, } \\
\text { practitioners, } \\
\text { teachers and peers }\end{array}$ \\
\hline
\end{tabular}

\section{Virtual Platform Typologies and Their Networked Learning Potentials}

Virtual realms have a potential to extensively redefine the existing realities and relationships between clients, architects, and experts from other disciplines or the relationships between teachers and students in architectural education. In this context, virtual environments and integrated Web 2.0 platforms can be seen as potential media for activating new types of educational approaches which cover novel research methods, theoretical knowledge from a broad range of disciplines, and facilitate collaborative knowledge construction in a network-based manner (McLoughlin \& Lee, 2011) (Fig. 6.1). 


\section{Networked Learning tools and}

Virtual Environments

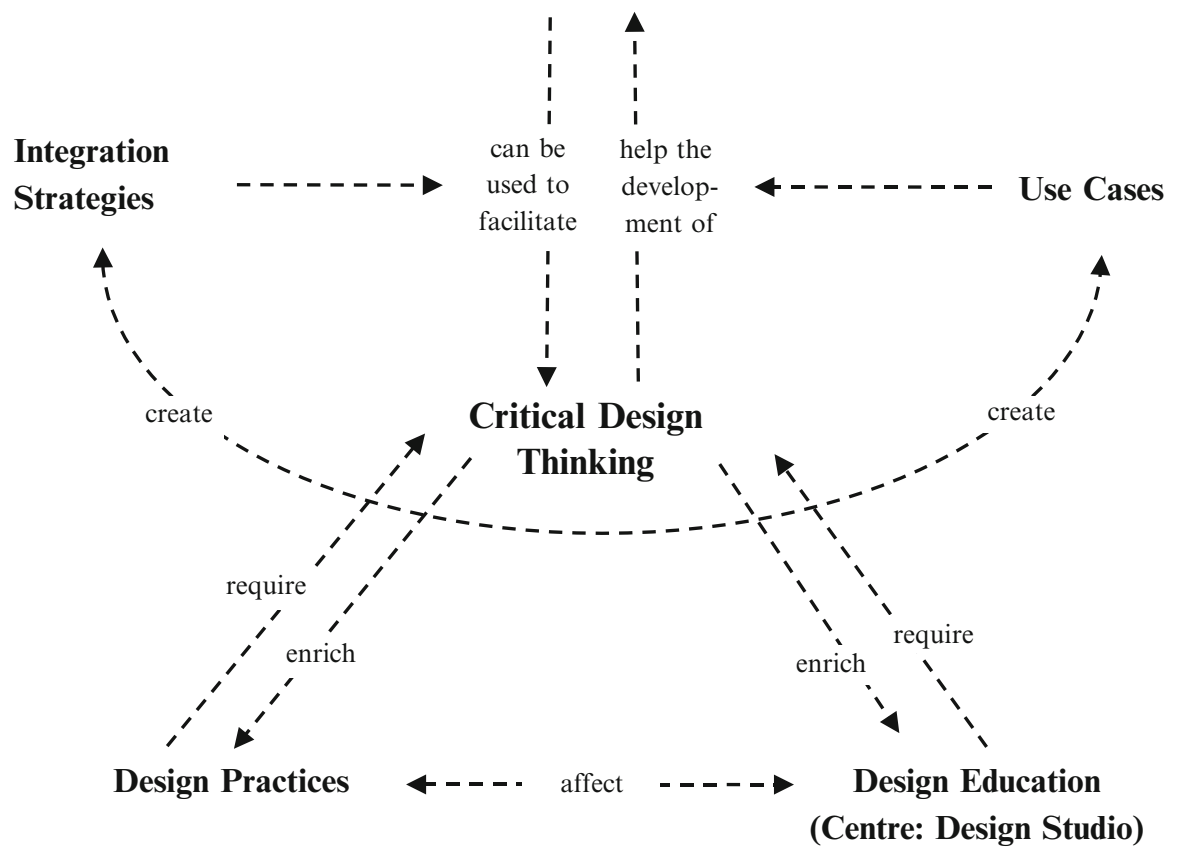

Fig. 6.1 A concept map revealing the addressed topics structured around the critical design thinking: design practices, design education, use cases, strategies and virtual tools/environments

As virtual environments are designed and developed by people, their properties can be set to reach specific aims. For instance, a virtual environment can focus on the stimulation of out-of-the box design thinking by introducing the absence of gravity or it can focus on stimulating debate and discussion between the different parties involved, thus focusing to certain communication modules. Some of these realms are specifically designed for certain aims and allow a certain degree of freedom for their use without degenerating into a 'tyranny of freedom' (Schwartz, 2000, p. 85).

In order to clarify the differences between these worlds, we mapped a wide array of possible virtual environments (Fig. 6.2) and explored their significance for architectural education (Pak \& Verbeke, 2012). Considering the variety of virtual environments and the fact that architectural education should be contextually embedded, we organised our typological effort on two axes to differentiate the relations between the environment and the content. The horizontal axis of analysis involves the evaluation of the environment of the virtual platforms based on Milgram, Takemura, Utsumi, and Kishino's (1994) reality-virtuality continuum. This continuum starts with 'a strictly real-world environment clearly constrained by the laws of physics' and ends up with 'a virtual reality environment in which the participant observer is totally immersed in a completely synthetic world'. On the vertical axis, we address 


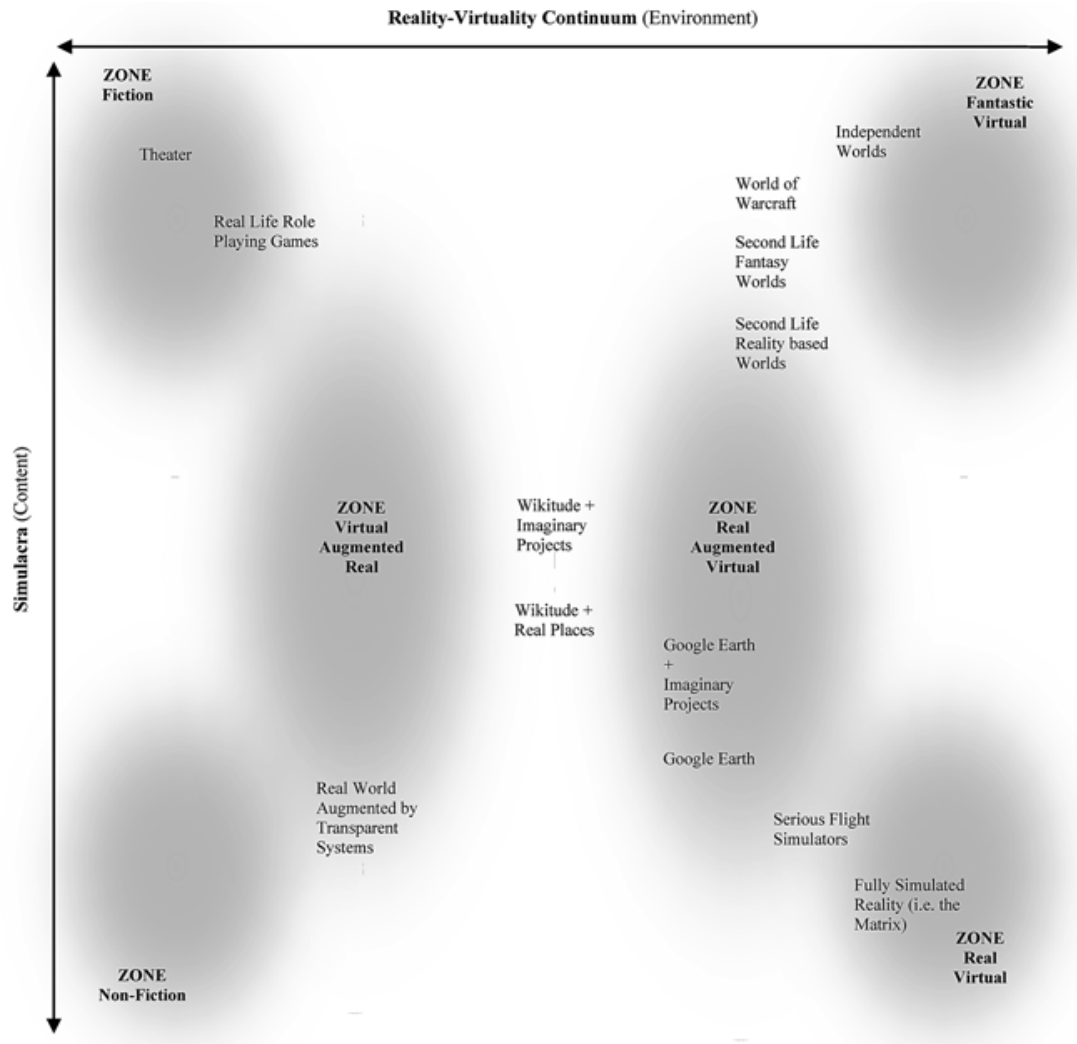

Fig. 6.2 Virtual platforms according to their contents and environments, including related concepts and 'zones'

the content that is being handled in these realms. With this purpose, we refer to the concept of the simulacrum, which goes back to Plato's ideas on image-making in his famous Sophist dialogues (Plato, Brann, Kalkavage, \& Salem, 1996; Deleuze, 1983).

In the dialogues, Plato makes a distinction between the image that is a faithful reproduction (or as good as possible) of the original and the copy that is an intentional deformation of the original. Baudrillard's $(1988,1994)$ simulacrum takes this concept further and differentiates between four successive phases of representation of a reality.

In the first phase the image is a good reflection of the original; in the second phase the image masks and perverts the reality; in the third phase the image masks the absence of the basic reality; and in the fourth phase, the image becomes its own pure simulacrum. While the copy resembles the original, the simulacrum has a totally different end: it gets a life of its own. That is why Baudrillard's conceptualisation is relevant for typological analysis of virtual environments and their usefulness for critical networked learning. 
In our diagram, the factual real is located at the bottom of vertical axis as it is a copy of the real that bears as much resemblance as possible. When we gradually move upwards, the content resembles the real world less and less. At the end of the axis are the unique virtual contents which are fundamentally different than the ones in the real world. These categories allow us to describe certain 'zones' in our diagram. These are: the real 'virtual', the virtual augmented real, the real augmented virtual and the 'fantastic' virtual.

\section{The Real 'Virtual' Zone}

When we speak of the 'real virtual' we refer to virtual environments that represent the real world, such as serious Virtual Flight Simulator games. It is clear that they are close representations of reality (and intend to be so); regarding the whole virtual environment, the architecture within it and the experience they try to evoke. The most extreme 'real virtual' is the fully simulated reality. It is a non-existent theoretical environment first introduced in Gibson's (1984) Neuromancer book as a virtual reality dataspace, which later inspired the Matrix movie by Wachowski Brothers (1999).

\section{The Virtual Augmented Real Zone}

This specific category refers to the use of ubiquitous augmented information systems connected to the real-world objects. Typical examples of the virtual augmented real are the pilot support systems which draw on information from integrated virtual environments, GPS data and pilot's line of sight measurement. Pilots experience the space as a predominantly real environment superposed with a virtual environment. Because of the technical complexity of these systems, architectural applications are so far limited to research projects. This category is closely related to the spaces which emerge as a combination of virtual environments and real structures. Bertuzzi and Zreik's (2011) mixed reality games for augmented cultural heritage can be considered in this zone.

\section{The Real Augmented Virtual Zone}

This type includes virtual environments where information from the real world is embedded into the virtual realm. Different than the virtual augmented real, majority of the spatial information is created and joined in a virtual system. Kinect Sports video game is a typical example of this typology. The majority of the game takes place in a multiplayer virtual environment and avatar behaviour(s) are augmented with real-life motion. Because of the relative affordability and mobility of their technical platforms, these types of applications have enormous potentials for urban design, user participation in planning and construction engineering waiting to be realised (Pak, Verbeke, \& Ag-Ukrikul, 2011). 


\section{The 'Fantastic' Virtual Zone}

Fantastic virtual environments are characterised as products of 'unrestrained imagination'. Massively multiplayer online role-playing games such as World of Warcraft or Everquest are examples of the fantastic virtual environments. Certain worlds that are created in the open simulator platforms can also be considered as fantastic, depending on the content and the configuration of the environments. At the first glance these types of games might look less useful in the field of architectural design education. However, by changing and reconfiguring the attributes and working principles of the virtual environments, it is possible to stimulate creativity and support collective thinking (Jakimowicz, 2002; Merrick \& Ning, 2011; Rosenman, Merrick, Maher, \& Marchant, 2006). For example, we can imagine and represent an environment in which people are not governed by the laws of gravity, which would allow the students to test their design strategies in this completely different setting. These kinds of educational practices can both be a liberating experience as well as a confrontation with traditional design thinking (Oosterhuis \& Feireiss, 2007).

\section{Non-virtual Fiction Zone}

This zone includes a rich world of pre-electronic games (e.g. chasing games, boardgames ...), plays and theatre which take place in the real world, occurring or existing in actuality. These can be claimed as the starting points and continuous sources of inspiration for many virtual games and worlds as well as architectural education (Sonmez \& Erdem, 2009; Yurekli, 2003).

\section{Non-fiction Zone}

In our chart, the non-fiction zone relates to the 'actuality' and includes things that are considered to be factually accurate and non-imaginary.

\section{Possibility of Mixed Zones}

It is important to add that in many situations, the virtual environments can travel between the described zones and/or cover multiple zones.

\section{Strategies for Fostering Critical Thinking in the Architectural Design Studio Using Virtual Environments}

\section{Moderation Without Autocracy}

We have stressed above that the studio, as the heart of architectural education, is the 'reflective practicum in designing' (Schön, 1983, p. 4). We have also elaborated on some of the current shortcomings, and in this section we illustrate the possibility of 
overcoming these shortcomings using virtual realms. Designing and working in virtual environments offers several possibilities regarding teaching and learning experiences. First, the design course does no longer need to be arranged in a physical place during certain hours (although we acknowledge that a physical meeting place every now and then will stay of major importance). Consequently, design as a process can be emphasised much more and the interaction between the teacher and the student can take on the form of an ongoing conversation as virtual realms offer the possibility of asynchronous communication and networked learning.

The designs of students can evolve based on discussions with tutors, and depending on the design of the realm, parallel development scenarios can be traced. Additionally, one can also benefit from interaction with the other participants in the realm, be it other tutors or students. A forum-which can take a myriad of representations in the realm-in which all ideas and comments come together can lead to a high level of interaction and unlock the possibility of crowd-sourcing as well as increasing mutual learning and co-creation. We might even envisage an independent virtual realm (see the 'fantastic virtual' typology in Fig. 6.2) in which the context for the design question has been constructed independently from real-world criteria. We can easily imagine a world in which no gravity exists, in which we can use a material with certain characteristics, and in which all the students, tutors and other participants can build/design their own projects. Participants can visit and experience each other's designs, perhaps add post-it comments, or maybe even manipulate the designs.

In such realms, it becomes clear that the importance is focused to process, communication techniques, teamwork and networked learning. Furthermore, a 'classical' design studio jury becomes very difficult, as the realms stimulate other ways of evaluation. They can stimulate the transition from the panopticon feeling of the design studio to a 'pantopicon' approach as defined by Novak:

While the panopticon describes a condition that is one-to-many, the conditions brought about by the pantopicon are both many-to-many, and one-as-many-to-many. We have reached a stage where all synchronic and diachronic knowledge is equally accessible. Distance in space-time is collapsing, and everything and everyone can enjoy an unparalleled, if disincarnate, proximity (Novak, n.d.).

Thus, the student is no longer submitted to the skewed power relation to a design jury but uses networked technologies to engage in 'a reflective conversation with the materials of the situation' (Schön, 1983, p. 4). This approach comes closer to the reality of the profession where the architect is in a constant conversation with clients, builders and other stakeholders about ideas, concepts and beliefs. People are connected in networks and especially architects, in their daily practice are in a constant communication and relations with others.

Carvalho and Goodyear (2014, p. 10) argue that networked learning can be understood as a practice that predates the computer age, but that has been often used as a synonym for online learning. When in 1998 the term networked learning was used by Goodyear et al. in a clearly pedagogical manner, it pointed precisely at the importance of the promotion of connections between learners and learners and tutor. This promotion largely happens through new ICT developments and online platforms. As such we see renewed opportunities of reintroducing the strength of working together in design projects. Networked learning offers students the possibilities to focus more on the process of design projects rather than on a 'perfect end state'. 
An end state that in reality will never be perfect, either because of the wishes and aspirations of the clients or because of 'random' coincidences out of your control (see as an illustration the work of the Belgian architect Lucien Kroll or the work of Rural Studio in the USA). The relation between networked learning and architectural practice is elaborated upon in the recent publication of Carvalho and Goodyear (2014, p. 17), where they point to some characteristics, typical of the architectural practice. They understand architecture as an indirect practice that has an effect on people through the built form. Architecture is further understood as neither arbitrary nor deterministic, it is multidisciplinary and flows across scales, from the broader context to the small detail. These characteristics again show how important debate and discussion is for the practice and thus these skills need to be developed during the educational trajectory.

Virtual environments can provide this opportunity for training. Virtual environments also offer the opportunity for clients with an extra medium to discuss and translate their desires and aspirations into formal creations. It is easy to imagine clients walking through virtually designed houses, experiencing different rooms and perhaps even changing things. For instance, we can imagine adding another window, enlarging the bedroom area, changing the colour of the tiles, bathroom, etc. This can be done asynchronously. Thus it becomes possible to question the more commonly assumed position of the architect as the one who holds the knowledge and wisdom and truly understands the world and its functioning. The Neo-Platonist idea of the architect as the 'philosopher-king' (Fishman, 1977) can be critically altered and architects should take on the role of critically engaged intellectuals, an attitude that also needs to be stimulated during the education.

Virtual environments can be considered novel because they enable 'learning as a social process' (Brown \& Adler, 2008) by creation of rich content through discussion and reflection. Besides providing three dimensional experiences, virtual environments entail new strategies, tools and techniques that encourage and augment informed, creative and social interaction. Introducing virtual realms which allow students to deal with socio-spatial challenges, spaces in which their design is constantly being challenged by possible users, by other designers, etc. helps them to constantly re-examine their own ideas and positions. In close relation to constructivist theories, a virtual environment-integrated design studio (in contrast with the traditional design studio) promotes community building and social learning rather than one-to-one face-to-face communication.

An example of a web-based geographic virtual environment for the collaborative, open-source and location-based analysis in the urban design studio is located in KU Leuven Faculty of Architecture, Campus Sint-Lucas Brussels (Fig. 6.3). In this studio, we have used a prototype developed specifically for the representation and communication of alternative urban development projects (Pak et al., 2011). In this context, it relates to the real 'virtual' zone in our typology represented in Fig. 6.2.

During the eight-week long experimental study, the students were able to effectively use the environment during the analysis phase of the urban design studio and created an online inventory that covers five gigabytes of analysis findings, sketches, photos, maps, studio presentations and texts describing their experiences. 
6 Virtuality and Fostering Critical Design Thinking...

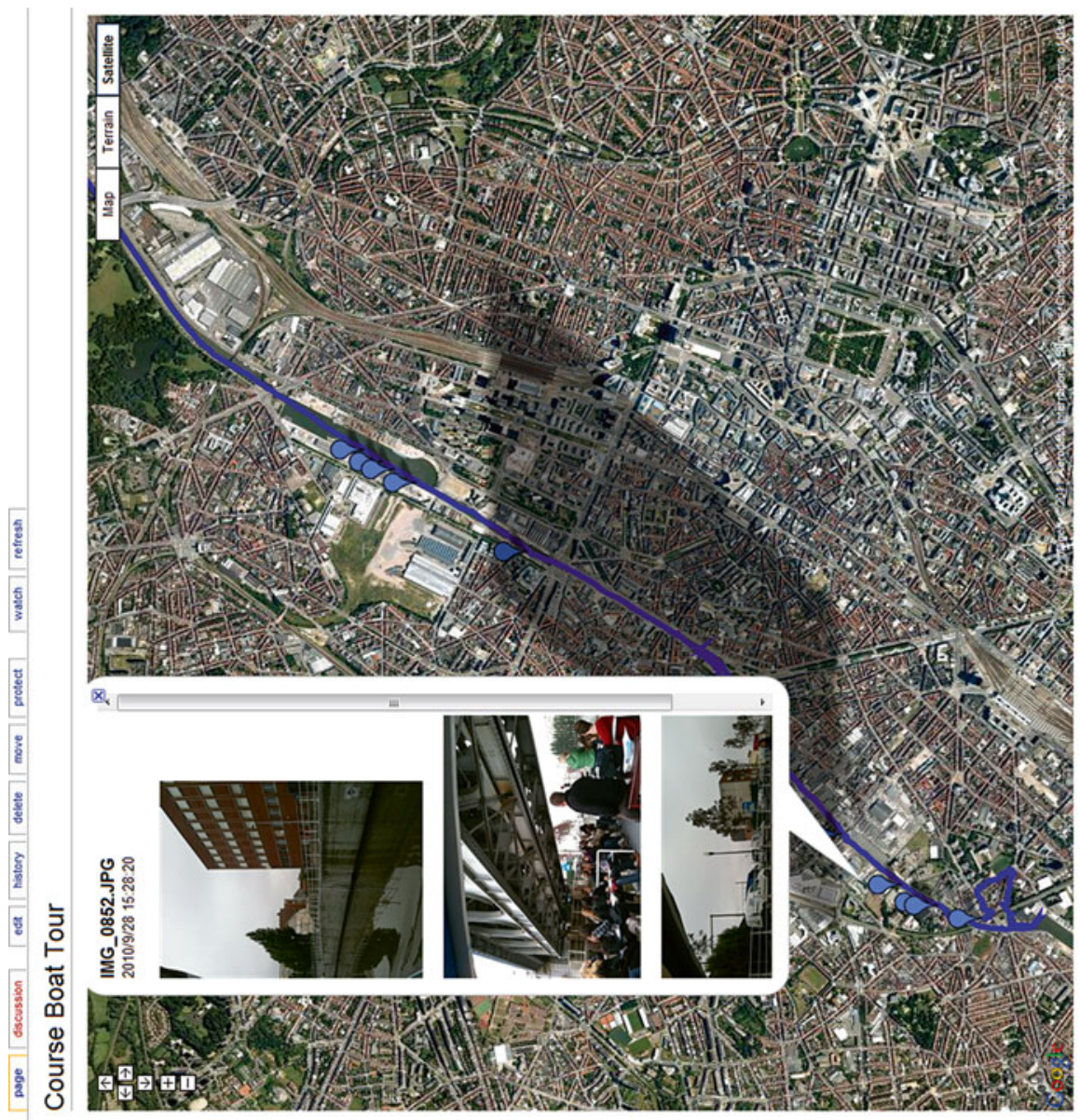

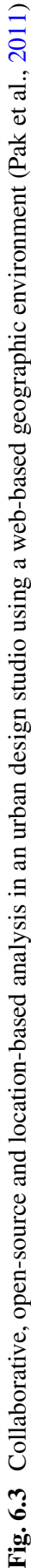




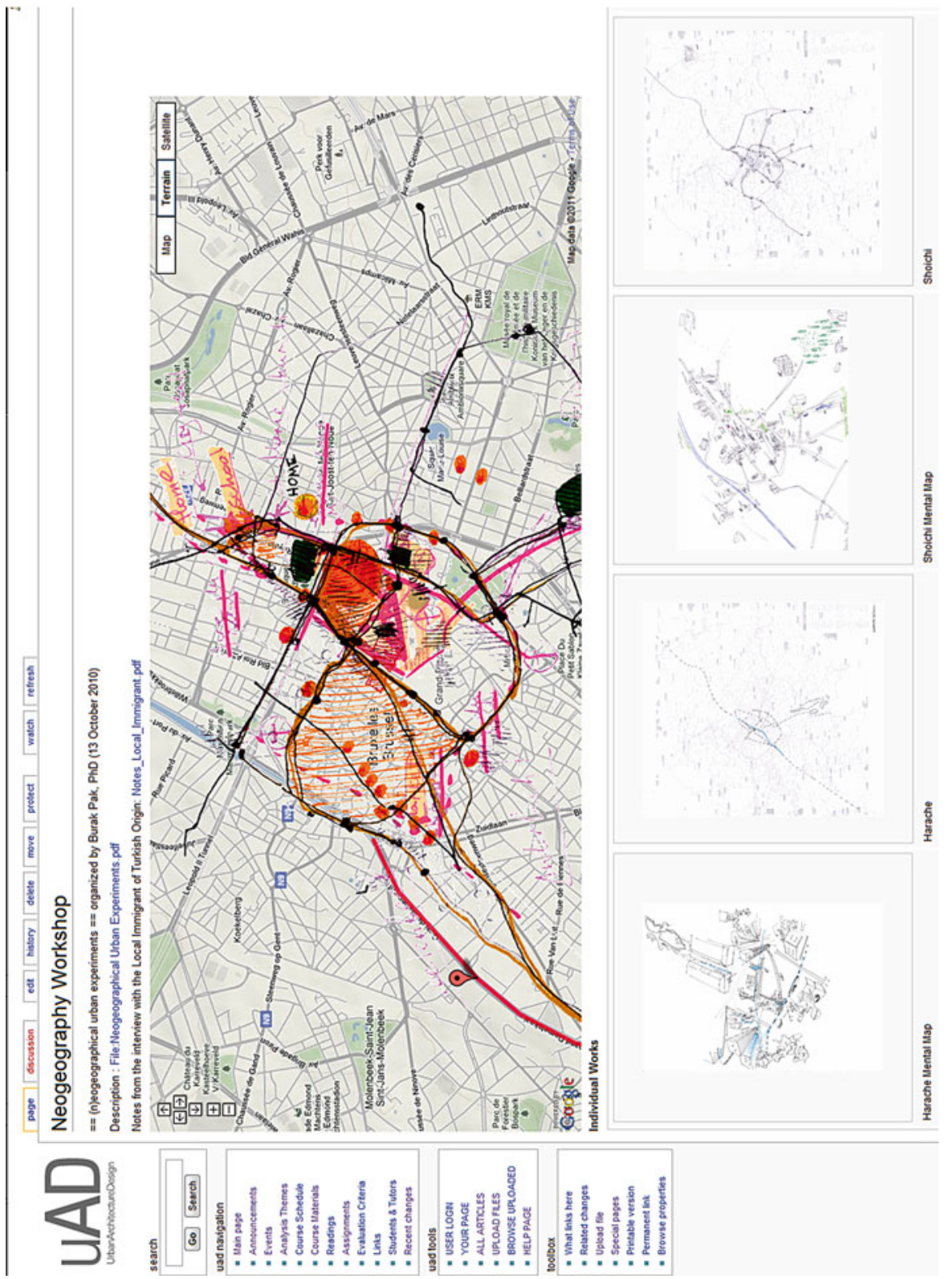



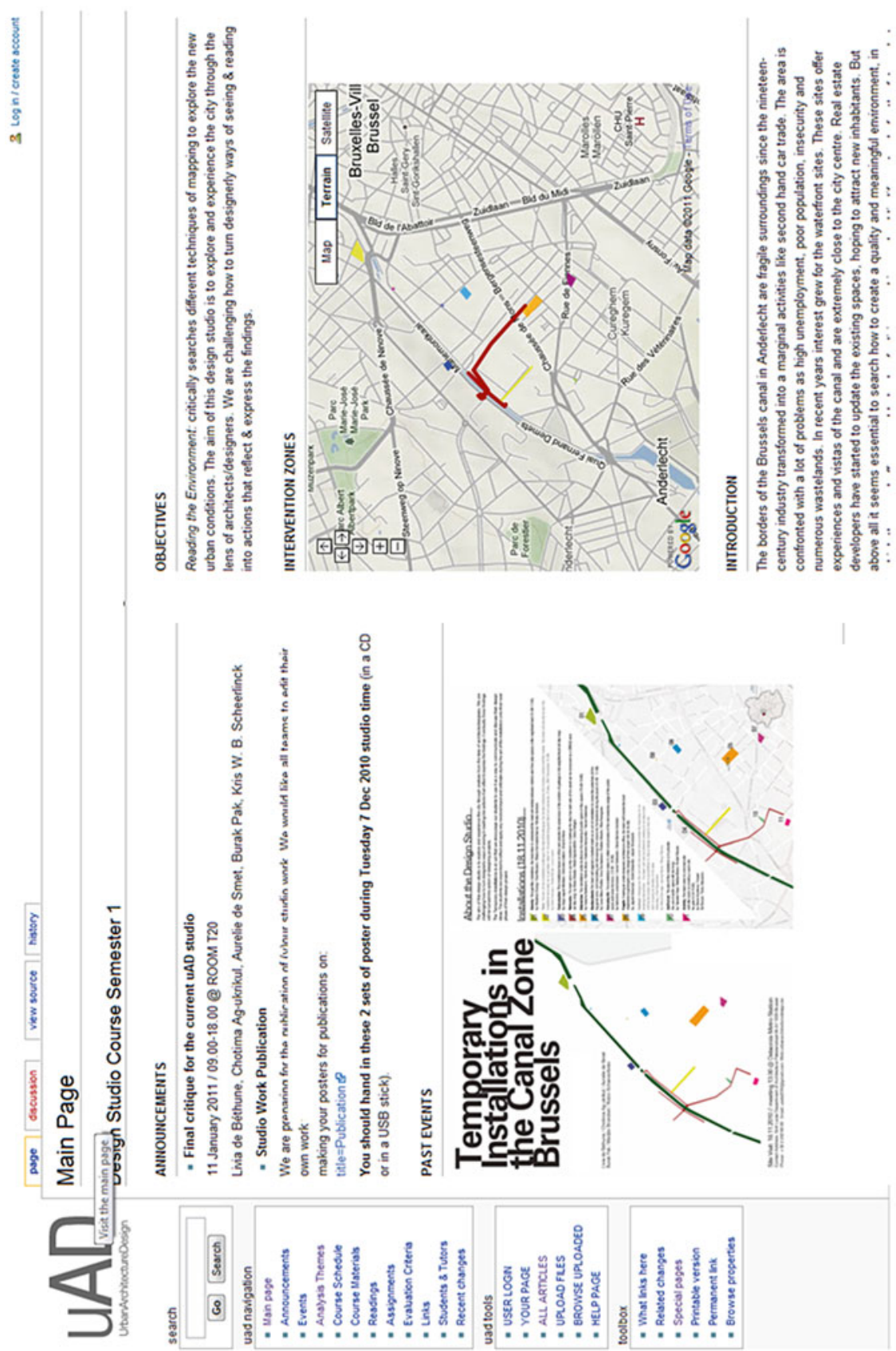


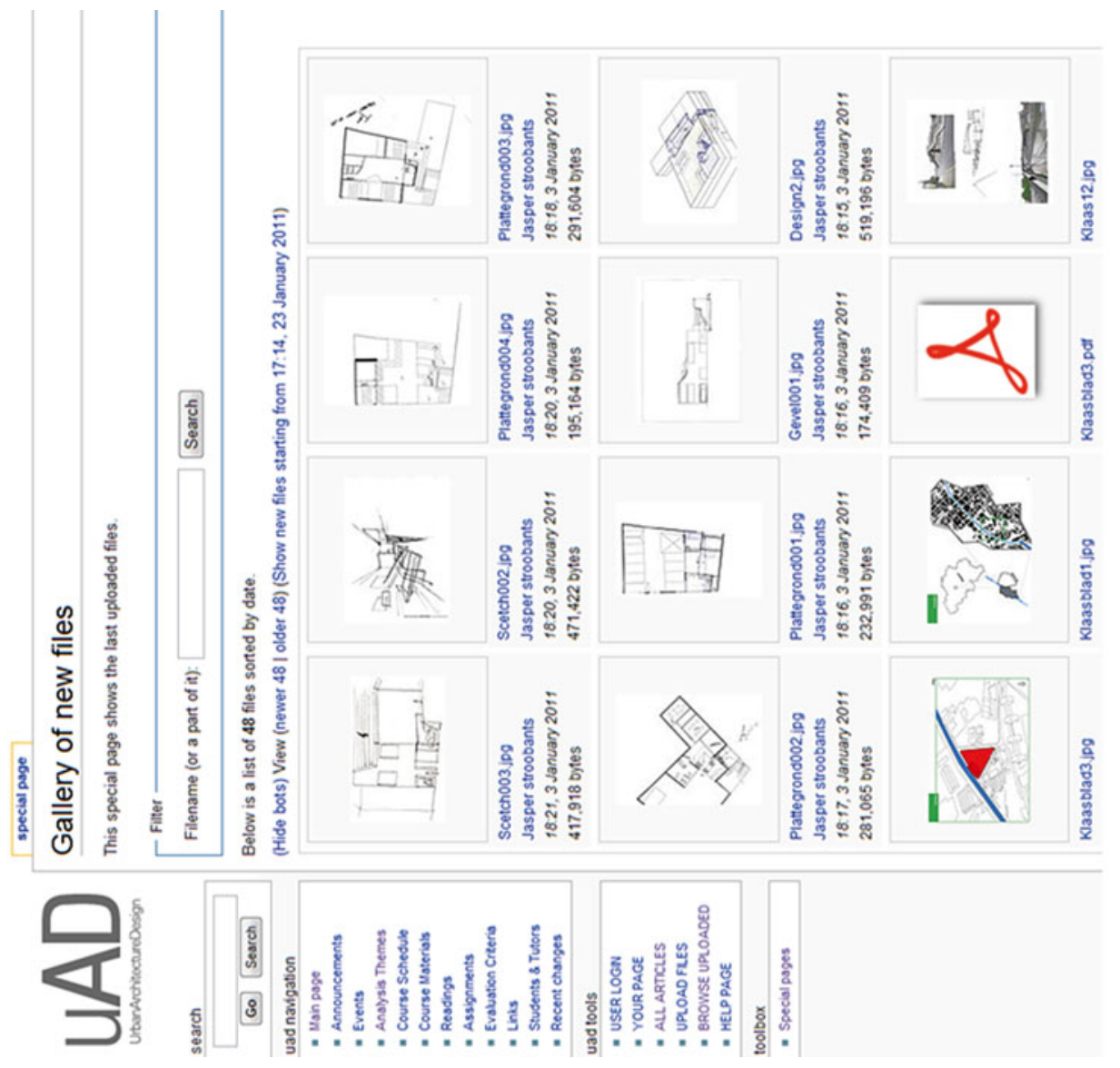


The proposed prototype provided opportunities for the transfer of the rich knowledge produced within the framework of a design studio to future studios, thus establishing a basis for the sustainable development of education and design ideas. The design studio coordinators were also assured that the body of knowledge represented in the virtual environment can potentially inspire their future students, and therefore we decided to use this environment as a major resource for future design studios.

We learned from this study that creating transparent and open studios can enhance the communication in architecture design education. The virtual environment that we tested in the proposed design studio context performed as a sustainable information platform for collecting and disseminating students' design information and motivated them to collaborate. We were also able to use the environment for following the progress of student works online on a regular basis, especially during the reflection process which took place in the design studio.

\section{Virtual Environments as a Sustainable Mirror Media for Increasing the Quality of Life in Real Worlds}

'Real' virtual environments can be considered as mirror spaces of real cities which facilitate participation of different disciplines - and most importantly-lay people in the development of new architectural and urban design projects. In this sense, virtual environments can contribute to the improvement of the built environment and the quality in real worlds.

It is clear that today people are increasingly involved within the public domain (in its broadest sense) and are increasingly voicing their own ideas and concerns regarding larger public projects. Nowadays, people are even able to stop large infrastructure projects. Consequently we want to argue that participation processes can benefit from a good integration with virtual environment possibilities. The work of Pak $(2009,2011)$ is exemplary as it shows that the use of virtual environments can stimulate participation processes and stimulate citizens to out their concerns regarding relevant issues.

Student architects could (and should) engage in such practices in the early phases of education. In this context, architectural schools can embrace the use of virtual environments by collecting student works and projects in sustainable and accessible virtual environments. For instance, student projects can be shared and experienced online with students, practising architects, experts and lay people to create live and interactive debates on increasing the quality of life in real environments. These kinds of practices can also help architectural schools to establish closer relations with society as well as facilitate the development of novel ways of creating a more participatory approach in architectural design. Specifically, the integration of experts from other disciplines can promote inter- and transdisciplinary knowledge transfer in an out-of-the-architectural-design field. This conversational approach will prove to be of importance when entering the professional field of architecture, 

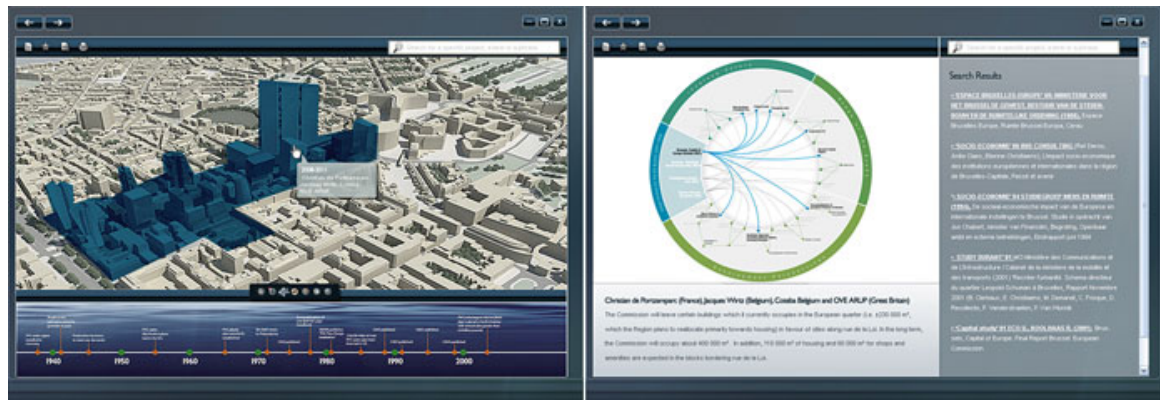

Fig. 6.4 Outline of the web-based geographic environment for communication, analysis and deliberation of alternative urban development projects (Pak et al., 2011)

as the architect discusses ideas, beliefs and concepts with his or her client and other experts involved in the construction and design process.

Unfortunately, the development of participatory and sustainable mirror-virtual platforms is still in progress and implementation of such environments requires high levels of expertise. Virtual platforms such as Second Life are not entirely suitable for these kinds of use cases. First, they are not designed to integrate real-life data from geographical information systems in real time; a feature necessary for providing contextual information that is essential for the evaluation of urban projects by the lay people and experts. Second, the objects cannot be assigned timestamps that can be controlled by the users in an interactive manner (also the length of animation is limited to 30s) which limits the ability of the world to represent multiple phases of a single project. Furthermore, mirror-virtual environments for public participation should be able to handle multiple forms of communication, synchronous, asynchronous and most importantly attached to certain feature(s) of a project in a locationbased manner. In this context, it is evident that further research is necessary for the activation of these kinds of integrative environments.

At this point we would like to present the virtual environment model outline (Fig. 6.4) that is created as a preliminary effort to create an alternative platform for the communication, analysis and deliberation of alternative urban development projects prepared for the Brussels Capital Region (Pak et al., 2011). This platform was developed with the contributions of Agency for Territorial Development and Brussels Environment Organization and is planned to be implemented and tested for the European quarter in Brussels. In its intended use, it relates to the virtual augmented real and fantastic virtual mixed zones described in Fig. 6.2.

We have also created educational use case scenarios for this platform in which student projects can be shared and experienced online with other students and teachers, practising architects, experts and lay people to create a live and interactive debate on increasing the quality of life in real environments (Fig. 6.5). This studio setup, which we call Design Studio 2.0, differs from the classical design studio described above in terms of available communication modes and styles, learning 


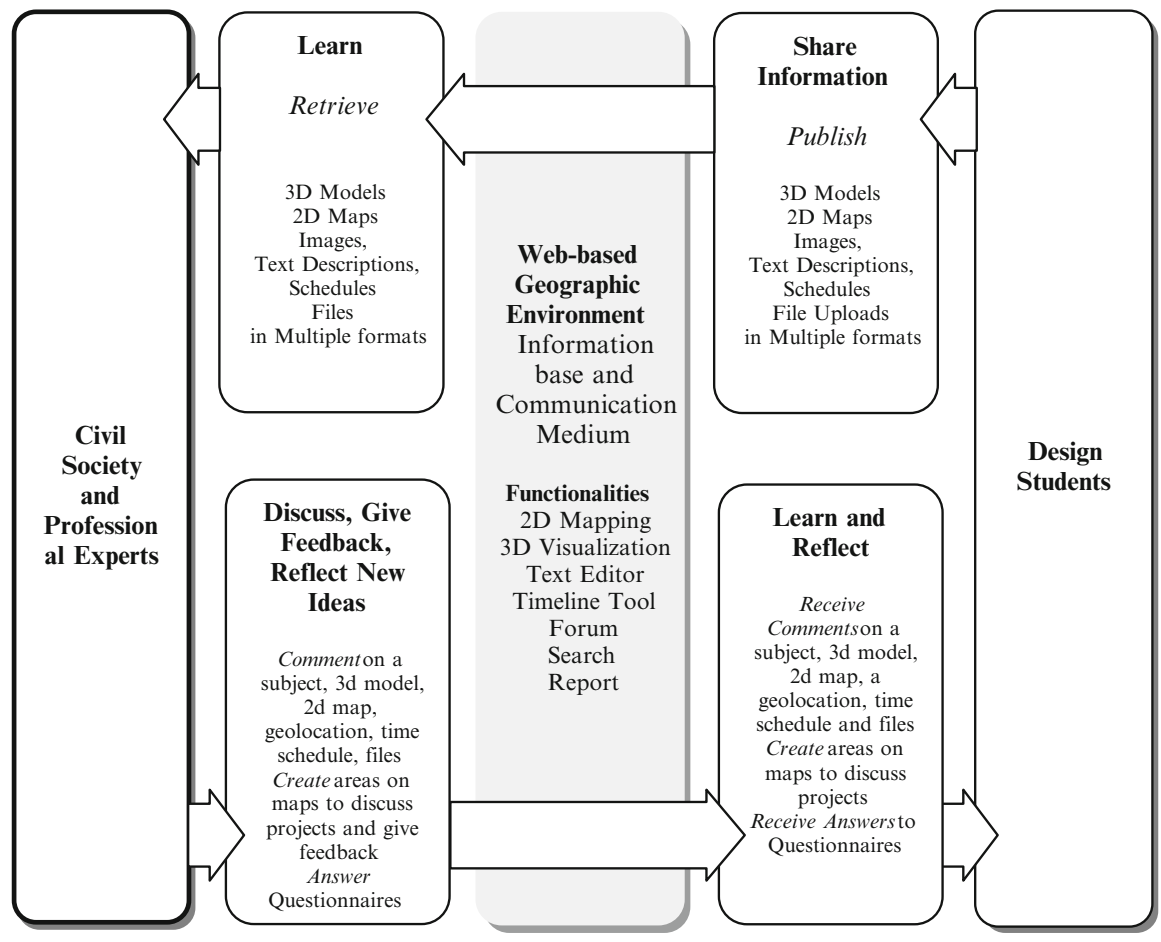

Fig. 6.5 The educational use scenario, actions and functions: reflection-in-action

experiences, studio focus, studio environment, time, information resources and representation of design information (Pak \& Verbeke, 2012):

- Design Studio 2.0 makes way to blended learning which refers to the combination of conventional and online learning activities.

- Compared with the conventional studio, the focus of the Design Studio 2.0 is more oriented towards the students and the critical learning processes.

- Design Studio 2.0 supports the design information to be shared in novel ways, including the use of 3D models (4D with the inclusion of time), scanned versions of sketches and drawings, computer drawings and renderings, dynamic maps, geolocated notes, and comments.

- Architects operate in a virtual world, a constructed representation of the real world of practice (Schön, 1987, p. 75). The Design Studio 2.0 learning environment extends this world to a shared and globally accessible virtual world creating novel potentials for collaboration.

- Learning in the Design Studio 2.0 can take place outside the school environment and is not limited to the studio hours.

- Besides the synchronous communication form, asynchronous and combined communication forms can be supported. 

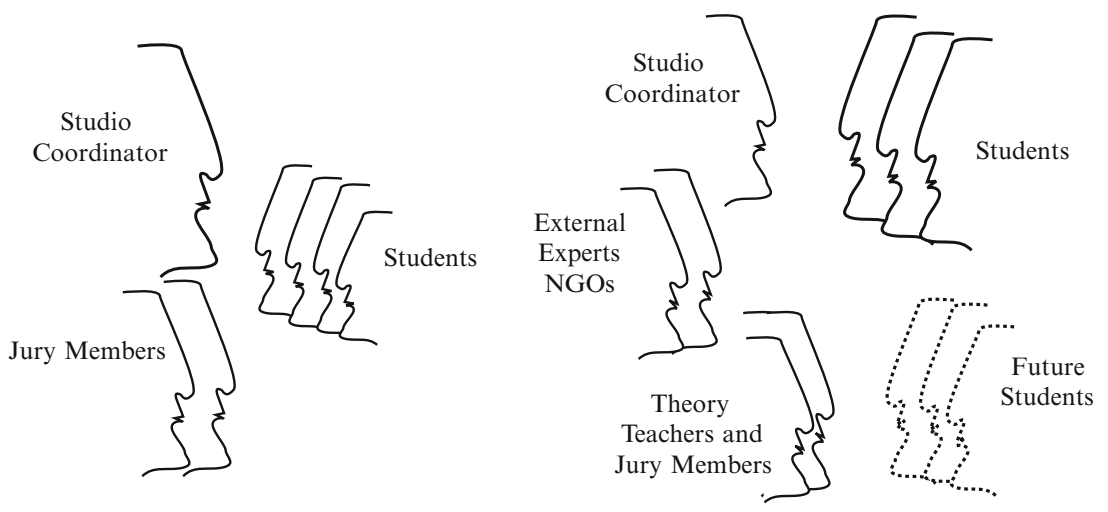

Fig. 6.6 Actors involved in the conventional and the proposed design studio setting

- While the conventional design studio involves face-to-face communication, the Design Studio 2.0 also facilitates avatar-to-avatar communication.

- Consequently, in the Design Studio 2.0 setting, it is possible to share the student works with the external experts and representatives of non-governmental organisations as well as students from different studios (Fig. 6.6).

Thus, this example illustrates the first steps of how a virtual environment stimulates an approach to urban design and architecture in which the process is more important than the end product, and enables a critical engagement of designers and stakeholders.

Before we move on to outlining some of the future challenges, we briefly want to highlight some of the opportunities introducing virtual worlds and networked learning approaches offer to the education of future architects and urban designers.

First, practising architecture entails constant conversations and discussions with a multitude of stakeholders. The current educational practice does not place enough emphasis on the importance of communication and working in teams. Introducing virtual realms in which an emphasis is placed on communication, both synchronous and asynchronous, enables a rediscovery of the opportunities of working together in a networked environment. Second, networked learning approach emphasises the social aspect of teaching and learning. Referring back to Argyris and Schön (1978) and Mezirow (1997), it is important that through the educational pathway students do not only acquire knowledge, but also re-examine their understanding of the world in relation to other people's ideas and positions. These insights can be developed in a networked learning environment, such as Design Studio 2.0, that offers students the possibility to openly discuss their ideas. Third, by developing these insights, networked learning environments can have an impact in the real world and its design. An important example in support of this claim is the current revaluation 
of participatory design approaches. While participation in design practices is currently often reduced to pseudo-participation and placation, we are convinced that fostering an attitude of dialogue and communication can potentially empower all stakeholders and reinforce their input from the initial conception of projects and designs to their possible realisation.

\section{Conclusions and Future Challenges}

This chapter connects the social turn in architecture practice and education with the innovative possibilities that emerge from the integration of virtual environments (in a broad sense) in design education. We demonstrate the current challenges for architectural education and argue that a critical design attitude is imperative to tackle the challenges facing future architects. On that basis, we argue that critical thinking can be stimulated through the networked learning pedagogy that connects back to the initial conceptualisation and theorised possibilities of studio-based learning approaches envisaged by Schön $(1983,1986,1987)$. Furthermore, we illustrate that critical thinking can even be enforced using new and innovative virtual learning environments. However, the complexity and inflexibility of the existing virtual and real learning environments are the biggest threats to integrated networked learning practices. At this point, two important factors need to be taken into consideration.

The first factor concerns difficulties associated with integration of 'innovative' virtual learning environments. In the educational context of architecture, these learning environments should provide more opportunities for critical reflexion than commonly used virtual learning environments. Instead of traditional communication, they should offer complex networked 3D-environments where the learners, and by extension the users, could interact in a multitude of ways, and which would offer opportunities to challenge the conditions of the virtual realm they are engaged in. Truly new insights and innovative pedagogies should arrive from the integration of virtual realms that can be found in the top right quadrant of Fig. 6.2, because these virtual realms offer the richest opportunities for experimentation for both teachers and students. However, complex virtual environments are sometimes not easily accessible for educators. Furthermore, capacities of such environments are sometimes far from well understood, and even easily dismissed under the classification of gaming and entertainment. Despite those limitations, this research clearly indicates that complex virtual environments offer sound opportunities to experiment with design and social implications of the practice of designing.

Secondly, we have observed the social turn in architectural practice. In a design practice that takes this social turn seriously, the architect-designer will acknowledge the needs and ideas of future users in a more radical way. According to Newton, 'The protagonist in the whole (urban) design practice is no longer the "expert" planner, but it is the informal community-based/grassroots process and the accompanying strategies and activism' (Miraftab, 2009). Central in this reasoning is the idea of critical design and critical thinking as a "mediation of theory and practice in social 
transformation' (Friedmann, 1987, p. 391). In this recalibrated role, the architect is expected to be critically immersed in the broader community. According to our findings, innovative virtual realms can be used to prepare the students for this role during their educational trajectories.

We would like to conclude with a number of remarks and suggestions related to more general concerns. The beginning of this chapter stresses the importance of infusing the architectural discipline with critical thinking and critical design grounded in the ideas and concepts of critical theory. Thus, in order to question the contemporary state of consumerism and capitalism, architects should engage with this current condition and actively seek to develop and imagine alternative urban futures (Brenner, 2009 and Eisenman, 2012). As suggested by Dunne and Raby (2011), this cannot be done in a mono-disciplinary manner, but in a continuous dialogue between people in different fields (from ethics to philosophy, from politics to biology). The chapter shows how integrating virtual realms and networked learning in design studio settings can stimulate students to adopt a critical approach to (architectural) design.

Adopting a critical attitude in architectural design practices and education should also include an in-depth questioning of learning processes and tools. Various types of virtual environments have different intrinsic properties which can potentially empower, enable and promote critical thinking and learning at different levels (Fig. 6.2). In order to enable critical learning practices in the design studio, it is necessary to couple these environments with custom tactics and strategies.

Virtual environments which can facilitate various communication, sharing and discussion modes do not magically enable critical thinking and collective learning. The overall planning, nature and content of networked teaching and learning should be sound and compatible with these aims. For instance, while involving external experts and lay people (users) into the design studio, it is also necessary to enable meaningful and productive interactions and positive dialogues between the involved parties. These require a significant amount of time dedicated to learning design and monitoring of the outcomes. Therefore, in order to create more innovative learning experiences, extra resources need to be allocated as a part of the general education strategy.

Furthermore, we have observed that promoting critical teaching and learning in the design studio raises general interconnected issues which naturally echo with political participation practices such as motivation, trust and equality. In order to be able to motivate the students to engage in critical conversations, it is necessary to break their conventional habits and promote a new understanding of criticism in the studio. One of the biggest challenges in this case is the students' reluctance to criticise each other's works in a rigorous manner. In this sense, establishing trust between students as well as the other participants is essential. At this point, ensuring equality in learning and critical discussions is a well-known (but difficult to reach) motivating factor which can increase the students' trust in the teacher as well as the value of the design studio itself. In addition, combining real-life and virtual learning activities, face-to-face meetings in real-life (especially in the case of involving experts) and thus enabling blended networked learning can increase the motivation and trust of the students. 
Last but not least, commercial virtual environments and social media platforms frequently violate their users' privacy by selling their personal information to third parties. Using these without anonymisation can lead to counter results conflicting with the aims of this research. Therefore, while facilitating networked learning, it is important to take measures to guarantee the privacy of the students, teachers and other involved actors. This can partly be achieved by self-hosting learning environments and data, relying on in-house/open-source software solutions and excluding commercial solutions.

\section{References}

Akin, O. (Ed.) (1997). Descriptive models of design activity. Design Studies, 18(4), 323-476.

Argyris, C., \& Schön, D. (1978). Organizational learning: A theory of action perspective. Reading, MA: Addison Wesley.

Banks, S., Goodyear, P., Hodgson, V., \& McConnell, D. (2003). Introduction to the special issue on : Advances in research on networked learning. Instructional Science, 31(1), 1-6.

Baudrillard, J. (1988). America. New York: Verso.

Baudrillard, J. (1994). Simulacra and simulation. Ann Arbor, MI: University of Michigan Press.

Bertuzzi, J., \& Zreik, K. (2011, November 16-18). Mixed reality games-Augmented cultural heritage, SIGraDi 2011. Proceedings of the 15th Iberoamerican Congress of Digital Graphics, Santa Fe, Argentina (pp. 304-307).

Bloch, E. (1995). The principle of hope. Cambridge, MA: MIT Press.

Boyer, E. L., \& Mitgang, L. D. (1996). Building community: A new future for architecture education and practice. A special report. Princeton, NJ: Carnegie Foundation.

Brenner, N. (2009). What is critical urban theory? City: Analysis of Urban Trends, Culture, Theory, Policy, Action, 15(2-3), 198-207.

Brown, J. S., \& Adler, R. P. (2008). Minds on fire: Open education, the long tail, and learning 2.0. Educause Review, 43(1), 16-32.

Carvalho, L., \& Goodyear, P. (2014). The architecture of productive learning networks. New York: Routledge.

Clark, M., \& Wilson, L. (1991). Context and rationality in Mezirow's theory of transformational learning. Adult Education Quarterly, 41(2), 75-91.

Cross, N. (2001). Designerly ways of knowing: Design discipline versus design science. Design Issues, 17(3), 49-55.

Cross, N. (2006). Designerly ways of knowing. London: Springer.

Cross, N., Christiaans, H., \& Dorst, K. (Eds.). (1996). Analysing design activity. Chichester, England: Wiley.

Davidson, C. (1995). Any place. Cambridge, MA: MIT Press.

De Graeve, P. (2010). Geen Universiteit zonder Kunsten-Pas d'Université sans Arts-No university without the arts. Gent: Faculteit Architectuur en Kunsten, Associatie K.U. Leuven.

De Laat, M. (2006). Networked learning. Apeldoorn, The Netherlands: Politie Academie.

Deleuze, G. (1983). Plato and the simulacrum. October, 27, 45-56.

Deleuze, G., \& Guattari, F. (2004). A thousand plateaus: Capitalism and schizophrenia. London: Continuum.

Dewey, J. (1933). How we think. Lexington, MA: DC Heath.

Dunne, A. (1999). Hertzian tales. London: Royal College of Arts.

Dunne, A., \& Raby, F. (2001). Design noir. The secret life of electronic objects. London: Birkhauser.

Dunne, A., \& Raby, F. (2011). Between reality and the impossible.

Eisenman, P. (2012). Eisenman talks architecture as politics (Interview). Retrieved October 20, 2013, from http://yaledailynews.com/blog/2012/10/31/eisenman-talks-architecture-as-politics 
Fishman, R. (1977). From radiant city to Vichy: Le Corbusier's plans and politics 1928-1942. In R. Walden (Ed.), The open hand: Essays on Corbusier. Cambridge, MA: MIT Press.

Foucault, M. (1980). The eye of power. In C. Gordon (Ed.), Power/knowledge: Selected interviews and other writings 1972-1977 by Michel Foucault (pp. 146-165). New York: Pantheon Books.

Foucault, M. (1982). The subject and power. Critical Inquiry, 8(4), 777-795.

Fraser, M. (2005). The cultural context of critical architecture. The Journal of Architecture, 10(3), 317-322.

Freire, P. (1970). Pedagogy of the oppressed. Harmondsworth, England: Penguin.

Friedmann, J. (1987). Planning in the public domain: From knowledge to action. Princeton, NJ: Princeton University Press.

Furedi, F. (2006). Where have all the intellectuals gone? Confronting 21st century philistinism. London: Continuum Press.

Gibson, W. (1984). Neuromancer. New York: Ace Books.

Giddens, A. (1976). New rules of sociological method. London: Hutchinson.

Goodyear, P., Banks, S., Hodgson, V., \& McConnell, D. (Eds.). (2004). Advances in research on networked learning. Boston: Kluwer Academic.

Goodyear, P; Hodgson, V., \& Steeples, C. (1998, October) Students experiences of networked learning in higher education. Lancaster: Lancaster University research proposal to the UK JISC.

Gramsci, A. (1992). Selections from the prison notebooks. New York: International Publishers.

Horkheimer, M. (1982). Critical theory. New York: Seabury Press.

Horton, M., \& Freire, P. (1990). We make the road by walking: Conversations on education and social change. Philadelphia, PA: Temple university Press.

Howland, M. (1985). On becoming an architect. Perspectives on the Professions, 5(1).

Jakimowicz, A (2002). Far Eastern International Digital Design Award (FEIDAD) Animation Category. Kolarevic.

Jencks, C. (1987). Le Corbusier and the tragic view of architecture. London: Penguin.

Jencks, C. (2011). The story of post-modernism: Five decades of the ironic, iconic and critical in architecture. London: Wiley.

Koch, A., Schwennsen, K., Dutton, T. A., \& Smith, D. (2002). The redesign of studio culture: A report of the AIAS studio culture task force. The American Institute of Architecture Students. Retrieved October 20, 2013, from http://archdesign.vt.edu/students/images/Studio_Culture_ Report_2002.pdf

Koutsabasis, P., Vosinakis, S., Malisova, K., \& Paparounas, N. (2012). On the value of virtual worlds for collaborative design. Design Studies, 33(4), 357-390.

Kuhn, S. (2001). Learning from the architecture studio: Implications for project-based pedagogy. International Journal of Engineering Education, 17(4-5), 349-352.

LAb[au] (n.d.). Weather Tower. Retrieved October 20, 2013, from http://lab-au.com/\#/projects/ weather-tower/

Lacan, J. (2006). The seminar of Jacques Lacan: The other side of psychoanalysis (Vol. XVII). New York: Norton.

Lefebvre, H. (1991). The production of space. Oxford: Blackwell.

Lepik, A. (2010). Small scale, big change: New architectures of social engagement. Basel, Switzerland: Birkhäuser.

Lloyd, M. (2010). There, yet not there: Human relationships with technology. Journal of Learning Design, 3(2), 1-13.

Machel, G. (2010). Education, financing and making good broken promises. Development, 53(4), 457-459.

Madanipour, A. (2010). Whose public space? International case studies in urban design and development. London: Routledge.

Mann, S. (2004). A personal inquiry into an experience of adult learning online. In P. Goodyear, S. Banks, V. Hodgson, \& D. McConnell (Eds.), Advances in research on networked learning. Boston: Kluwer Academic.

Marcuse, P. (2009). From critical urban theory to the right to the city. City: Analysis of Urban Trends, Culture, Theory, Policy, Action, 13(2), 185-197. 
McLoughlin, C., \& Lee, M. J. W. (2011). Pedagogy 2.0 in Web 2.0-based e-learning: Applying social informatics for tertiary teaching. Hershey, PA: Information Science Reference.

Melles, G., \& Feast, L. (2013). Design thinking and critical approaches: The pragmatic compromise. In T. Vaikla-Poldma (Ed.), Meanings of designed spaces (pp. 360-369). London: Bloomsbury.

Merrick, K, \& Ning, G. (2011). Supporting collective intelligence for design in virtual worlds: A case study of Lego Universe. In Proceedings of CAAD Futures 2011. Messinger, Belgium.

Mezirow, J. (1981). A critical theory of adult learning and education. Adult Education Quarterly, 32(1), 3-24.

Mezirow, J. (1997). Transformative learning: Theory to practice. New Directions for Adult and Continuing Education, 1997(74), 5-12.

Milgram, P., Takemura, H., Utsumi, A., \& Kishino, F. (1994). Augmented reality: A class of displays on the reality-virtuality continuum. In H. Das (Ed.), Proceedings of telemanipulator and telepresence technologies (pp. 282-292). Boston: MIT Press.

Miraftab, F. (2009). Insurgent planning: Situating radical planning in the global south. Planning Theory, 8(1), 32-50.

Newton, C. (2013). Into the urban beyond. In C. Boano, W. Hunter, \& C. Newton (Eds.), Contested Urbanism in Dharavi. Writings and projects for the resilient city. London: UCL.

Newton, C., \& Boie, G. (2011). Resuscitating the architect in a technology-driven discipline-The case of the fragile project. In M. Voyatzaki \& C. Spiridonidis (Eds.), Proceedings of EAAE International Conference: Rethinking the human in technology-driven architecture. Chania, Greece: European Association for Architectural Education.

Novak, M. (n.d.). Trans terra form: Liquid architectures and the loss of inscription. Retrieved January 20, 2013, from http://www.krcf.org/krcfhome/PRINT/nonlocated/nlonline/nonMarcos. html

Oosterhuis, K., \& Feireiss, L. (2007). Game Set and match II, on computer games, advanced geometries and digital technologies. Rotterdam, The Netherlands: Episode Publishers.

Pak, B. (2009). Design decisions and activities in computer-aided and conventional architectural design process. $\mathrm{Ph} . \mathrm{D}$. Thesis, Istanbul Technical University, Istanbul.

Pak, B. (2011). A virtual environment for analysis and evaluation of alternative urban development projects for the Brussels capital region. Project Report. Brussels: Institute for the Encouragement of Scientific Research and Innovation of Brussels.

Pak, B., \& Newton, C. (2015). Eversion as a Generative Metaphor for Situating Virtual Worlds in Architectural Design Education. In S. Gregory, M. Lee, B. Tynan, \& B. Dalgarno (Eds.), Virtual worlds in online and distance education. Athabasca: Athabasca University Press.

Pak, B., \& Verbeke, J. (2012). Design Studio 2.0: Augmenting reflective architectural design learning using social software and information aggregation services. Journal of Information Technology in Construction, 17, 502-519.

Pak, B., Verbeke, J., \& Ag-Ukrikul, C. (2011). An "Open-Source" International Urban Design Studio organized in Brussels, Utilizing a Web-based Geographic Virtual Environment Prototype for the Collaborative Analysis of a Fragile Urban Area. In Proceedings of Education and Research in Computer Aided Architectural Design in Europe (eCAADe) conference, University of Ljubljana (UL), Slovenia.

Pak, B., Newton, C. (2015). Eversion as a Generative Metaphor for Situating Virtual Worlds in Architecture and Urban Design Education, Virtual Worlds in Online and Distance Education. In S. Gregory (Ed.), Issues in Distance Education series. New York: NOVA Science Publishers.

Peters, R. (1965). Education as initiation. In R. D. Archambault (Ed.), Philosophical analysis and education. London: Routledge \& Kegan Paul.

Plato, Brann, E., Kalkavage, P., \& Salem, E. (1996). Plato's Sophist, or, the professor of wisdom. Newburyport, MA: Focus.

Rancière, J. (1991). The ignorant schoolmaster: Five lessons in intellectual emancipation. Stanford, CA: Stanford University Press.

Rosenman, M., Merrick, K., Maher, M., \& Marchant, D. (2006). DesignWorld: A multidisciplinary, collaborative design environment using agent-based virtual worlds. In Proceedings of 
the Second International Conference on Design Computing and Cognition. Eindhoven, The Netherlands.

Schnabel, M. A., \& Ham, J. J. (2011). Web 2.0 virtual design studio: Social networking as facilitator of design education. Architectural Science Review, 54, 108-111.

Schön, D. (1983). The reflective practitioner: How professionals think in action. New York: Basic Books.

Schön, D. (1986). The design studio: An exploration of its traditions and potential. London: Royal Institute of British Architects.

Schön, D. (1987). Educating the reflective practitioner: Toward a new design for teaching and learning in the professions. San Francisco: Jossey-Bass.

Schuermans, N., \& Newton, C. (2012). Being a young and foreign researcher in South Africa: Towards a postcolonial dialogue. Singapore Journal of Tropical Geography, 34(2).

Schwartz, B. (2000). Self-determination: The tyranny of freedom. American Psychologist, 55(1), $79-88$.

Shotter, J. (1993). Cultural politics of everyday life: Social constructionism, rhetoric and knowing of the third kind. Buckingham, England: Open University Press.

Simon, H. (1969). The sciences of the artificial. Cambridge, MA: MIT Press.

Smith, E. (2011). Teaching critical reflection. Teaching in Higher Education, 16(2), 211-223.

Sonmez, O. \& Erdem, A. (2009). Design games as a framework for design and corresponding system of design games. In Computation: The New Realm of Architectural Design, 27th eCAADe Conference Proceedings. Technical University, Istanbul, Turkey.

Steier, F. (1991). Reflexivity and methodology: An ecological constructionism. In F. Steier (Ed.), Research and reflexivity. London: Sage.

Till, J. (2009). Architecture depends. Cambridge, MA: MIT Press.

Valkenburg, A. (2001). Schön revised: Describing team designing with reflection-in-action. In P. A. Lloyd \& H. Christiaans (Eds.), Proceedings of DTRS 5 (pp. 315-329). Delft, The Netherlands: DUP Science.

Wachowski Brothers (1999).The Matrix [Motion picture]. Warner Brothers, USA.

Wang, T. (2010). A new paradigm for design studio education. International Journal of Art \& Design Education, 29(2), 173-183.

Webster, H. (2006). A foucauldian look at the design jury. Art, Design and Communication in Higher Education, 5(1), 5-19.

Wilson, T. (2002). Strangers to ourselves: Discovering the adaptive unconsciousness. Cambridge, MA: The Belknap Press of Harvard University Press.

Yurekli, I. (2003). Play in architectural design education. Ph.D. Thesis. Technical University Faculty of Architecture, Istanbul, Turkey. 